\title{
A FORMAÇÃO MILITAR SOB O ENFOQUE DE RELAÇÕES DE GÊNERO: UMA EXPERIÊNCIA
}

\author{
Emilia Emi Takahashi'
}

\section{Resumo}

Este estudo tem como objetivo apresentar uma interpretação do processo de formação militar, considerando a entrada das mulheres, como cadetes, na única Academia das Forças Armadas a admiti-las em seus cursos de formação de oficiais no Brasil. Partindo de um enfoque sociológico dado à instituição militar e aos princípios que orientam a conduta neste tipo de instituição, coloca em discussão as relações de gênero decorrentes da participação da mulher. Ao final, traz dados de uma pesquisa empírica, sobre as vivências e representações de cadetes das primeiras turmas mistas acerca da profissão militar.

Palavras-chaves: gênero e formação militar.

\section{INTRODUÇÃO}

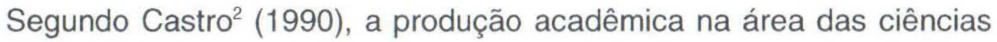
sociais sobre militares é extensa, porém, a maioria destes estudos tende a "politizar" a instituição militar, ao priorizar a análise do papel dos militares na política brasileira. Seja devido ao difícil acesso às organizações militares, ou talvez ao "trauma" causado pelas intervenções armadas no cenário político, o fato é que poucos estudos tratam a instituição militar como um objeto legítimo de análise.

Considerando que a partir da década de 70 boa parte dos exércitos ocidentais passou a admitir mulheres em suas fileiras, e que a Academia da Força Aérea é a única das Forças Armadas a admitir mulheres como cadetes no Brasil, conhecer a perspectiva institucional, privilegiando o processo de formação profissional dos/as cadetes, permite o preenchimento da lacuna apontada por Castro, bem como abre a possibilidade de se estudar a instituição militar como um novo espaço de atuação da mulher.

A problemática de um estudo que versa sobre a formação profissional e relações de gênero dentro de uma instituição militar tem a ver com o estudo do poder e requer a formulação de um referencial teórico que permita uma visão de conjunto dos temas estudados. Assim, a partir de um enfoque sociológico dado à escola militar e aos princípios que orientam o comportamento dos indivíduos nessas instituições, este artigo também coloca em evidência algumas contribuições teóricas que evidenciam as relações de

1 Psicóloga, Mestre e Doutora em Educação (UNICAMP), Professora Adjunto da Academia da Força Aérea e Membro do Núcleo de Psicologia Política da PUC-SP. E-mail: emi003@terra.com.br

2 Trata-se de Celso Castro, antropólogo, cuja pesquisa sobre a formação de cadetes do Exército no final da década de 80 , constitui um marco histórico-acadêmico no Brasil. Ver referências 
poder que os estudos sobre instituição militar e gênero suscitam. Ao final apresentamos dados de uma pesquisa empírica ${ }^{3}$ sobre o processo de formação profissional em si e algumas reflexões sobre a instituição militar como um novo espaço de formação e atuação das mulheres.

\section{RELAÇÕES DE PODER}

Em sua análise sobre Estado, política e seus componentes - poder, dominação e força, Weber (1977 e 1979) valoriza o sentido e as abstrações das relações dos homens entre si e com as instituições. Por exemplo, ele define a dominação como sendo uma forma de poder presente da ação comunitária, que se traduz em uma relação social na qual a ordem emitida pelo dominador influi sobre os atos dos dominados de tal forma e em um grau socialmente relevante que estes a cumprem como se a tivessem adotado por si mesmos. Além disso, segundo sua análise, a dominação é garantida por mecanismos legitimadores que determinam o tipo de relação de dominação que se estabelece. Analisando as estratégias que os dominadores utilizam para garantir sua dominação e as crenças que os dominados possuem para aceitarem sua submissão, Weber salientou três motivos de legitimidade que determinam três tipos de dominação que se estabelecem por meio de estruturas sociológicas distintas:

1. por meio de um hábito cego de lealdade a quem dispõe dos meios de coerção - dominação racional-legal;

2. por meio da obediência a regras tradicionais, que se perderam no tempo - dominação tradicional;

3. em obediência a um carisma pessoal de alguém que se coloca como portador de uma missão de salvação - dominação carismática.

Segundo Weber, os tipos de dominação não se excluem, mas na maioria das vezes eles se mesclam. O tipo mais puro de dominação racionallegal é a burocracia, a idéia básica que permeia esse tipo de dominação é a de que qualquer direito pode ser criado e modificado perante um estatuto sancionado corretamente no que diz respeito a sua forma. Obedece-se à pessoa não em virtude do seu direito próprio, mas da "regra instituída" (1977, p. 708), ou seja, o direito de mando é legitimado por regras racionais e impessoais. Tanto a dominação tradicional quanto a carismática podem sofrer um processo de "burocratização", pois ambas são muito instáveis e carecem de um estatuto que defina quem manda e quem é mandado, os direitos e deveres de cada um, uma hierarquia, um conjunto de regras que dê estabilidade à dominação ${ }^{4}$.

3 Trata-se da tese de doutorado da autora intitulada "Homens e mulheres em campo -um estudo sobre a formação da identidade militar", defendida na Universidade Estadual de Campinas UNICAMP em 2002.

4 Em virtude do nosso estudo ter como objeto a instituição militar - baseada na dominação burocrática, não nos dedicaremos aos outros dois tipos de dominaçăo analisados por Weber. 
A formação dos Estados modernos foi estudada por Weber como um processo de concentração de meios administrativos e militares legais. Em sua análise, antes do período moderno, os exércitos eram entendidos como forças independentes, contratadas para o exercício de dominação pessoal. A formação dos Estados modernos, no entanto, prescindiu da monopolização dos meios de dominação, entre eles, os exércitos, que foram então institucionalizados e passaram a ser utilizados pelos Estados como instrumentos de dominação política (da burguesia, da democracia...). A criação dos exércitos permanentes possibilitou a formação dos Estados modernos e gerou uma nova configuração destas organizações que foram burocratizadas: tiveram seus contingentes separados em função da especialidade das armas: passaram a ser comandadas por chefes militares, entre outras modificações.

Para Weber, o grande segredo da burocracia é a capacidade de desenvolver um certo tipo de "racionalização" que permeia as relações sociais por meio do processo de socialização (1977); daí o nosso interesse em seus estudos para conhecer e analisar o processo de formação profissional que se desenvolve dentro de uma organização (militar) estruturada com base racionallegal.

Goffman (1978 e 1996), em sua tentativa de construir uma versão sociológica da estrutura do "eu" que se forma em uma determinada organização, relata como é fechada e formalmente administrada a vida dos indivíduos que trabalham e vivem separados da sociedade mais ampla por considerável período de tempo nas chamadas "instituições totais".

Como características comuns, as instituições totais possuem uma grande barreira à relação social com o mundo externo, e a proibição à saída que muitas vezes estão incluídas no esquema físico, como portas fechadas, paredes altas, arame farpado e guaritas. Se nas demais instituições um indivíduo tende a brincar, dormir e trabalhar em diferentes lugares, nas instituições totais a tendência é a de romper as barreiras que comumente separam estas três esferas da vida, de modo que todos os aspectos da vida sejam realizados no mesmo local e sob uma mesma autoridade; todas as atividades realizadas diariamente envolvam a companhia de um grande grupo de pessoas tratadas da mesma forma e obrigadas a fazer as mesmas coisas em conjunto; todas as atividades diárias sejam tão rigorosamente estabelecidas em horários, pois uma atividade leva, em um tempo prédeterminado à seguinte, e todas elas são impostas de cima, por um sistema de regras explícitas; as várias atividades obrigatórias sejam reunidas num plano racional único, supostamente planejadas para atender os objetivos oficiais da instituição. (1996)

O interesse sociológico de Goffman pelas instituições totais reside no fato de que elas, além de constituírem um híbrido social que abrange tanto a comunidade residencial quanto a organização formal, criam e mantém um tipo específico de tensão psicológica entre os internos para utilizá-la como força estratégica no controle dos próprios. Como condições facilitadoras desta tensão psicológica, Goffman cita, entre outras, o enfraquecimento da autonomia e da liberdade de ação, o uso de racionalizações criadas para controlar a vida diária em espaço e com recursos restritos, a ruptura com o mundo externo e com os papéis anteriores para criar um grupo homogêneo de 
pessoas codificadas e conformadas, e a modelação suave por meio das obrigações de rotina.

A conseqüência básica da estrutura das relações sociais nas instituições totais é o controle de muitas necessidades humanas por uma administração burocrática, que visa à modelação do eu dos internos e que pode provocar uma tensão psicológica aguda para alguns, ou um alívio psicológico para aqueles indivíduos desiludidos com a sociedade mais ampla.

Ao estudar $\Theta$ processo de socialização que ocorre com os cadetes na AMAN, Castro (1990) tece algumas críticas com relação à utilização do modelo de instituição total apresentado por Goffman em estudos que privilegiam os aspectos internos das instituições militares, especificamente em academias. Segundo Castro, em primeiro lugar, quando se trata de um estudo em academias, temos que considerar que nestes locais, apesar da criação de "tensões persistentes" como estratégia de controle dos internos, os cadetes conseguem se ver em uma situação passageira, numa etapa de sua formação a ser superada. Além disso, Goffman trata principalmente de estabelecimentos de participação compulsória, sendo que a participação dos cadetes em uma academia não é exclusivamente compulsória.

A maior crítica que Leirner (1997) faz à analise das instituições militares inspirados nos moldes das instituições totais descritas por Goffman é que, embora esclareçam sobre a cadeia disciplinar, pouco esclarecem quanto à multiplicidade de dimensões da vida social militar.

Apesar das divergências sobre o estudo de instituições militares apontadas por Castro e Leirner, a referência aos estudos de Goffman sobre instituições totais é necessária em um estudo sobre o processo de formação de identidade militar, dada sua relevância e pioneirismo no estudo de instituições relativamente autônomas em relação ao mundo exterior.

Foucault (1977 e 1979) oferece algumas interpretações de aspectos próprios do poder disciplinar que permitem analisar a instituição militar como o local onde o poder recompensa, permite estabelecer hierarquias, controla o tempo, vigia espaços, classifica e pune.

Segundo a análise de Foucault, os corpos precisam ajustar-se a determinados movimentos, ritmados em um tempo preciso, com certa duração, ordem de sucessão e com maior rigor no interior das instituições do tipo militares. A vigilância constante faz com que a comunicação entre os indivíduos se realize num sentido vertical, provocando o isolamento, reforçando a hierarquia e favorecendo o controle ininterrupto, podendo ocorrer inclusive através do olhar (1977). O controle dos espaços ocorre através de uma arquitetura bem planejada que favorece a vigilância interior. Como é possível perceber, Foucault oferece uma gama de aspectos que podem ser analisados à luz das relações sociais que ocorrem no interior da caserna.

Foucault também se posiciona de modo a oferecer uma dura análise dos limites dos conceitos que tendem à universalidade, desenvolvendo uma refinada reflexão sobre o poder, destacando seu caráter relacional, situacional e dinâmico. A história da produção do conhecimento que pousa sobre a revelação de conceitos universais é rejeitada e, mais do que o sentido das coisas, ele busca a sua construção. Para tanto, ele invoca toda a trama histórica para dar conta da constituição dos saberes e critica os referenciais 
que se supõem universalizantes em sua representação por se basearem naquilo que é "justo por razão e por natureza", com esta advertência, ele evidencia os limites de análises anteriores que se baseavam ou no jurídico ${ }^{5}$, ou no Estado $^{6}$, ou ainda no próprio sujeito constituinte ${ }^{7}$.

Um outro elemento importante da teoria de Foucault é o tratamento que ele dá ao espaço, considerado como o solo em que se inscreve o poder e justifica: "desde o momento que se pode analisar o saber em termos de região, de domínio, de implantação, de deslocamento, de transferência, pode-se aprender o processo pelo qual o saber funciona como um poder e reproduz os seus efeitos" (1979, p.158). Mais do que o solo, o território, Foucault enfatiza a necessidade de trazer o espaço institucional para a análise do poder, de revelar como a arquitetura pode ser utilizada estrategicamente para o controle do indivíduo ou da população, por exemplo em hospitais, escolas, prisões ou centros urbanos ${ }^{8}$.

Ao falar da produção de saberes, Foucault atenta para o discurso em torno do poder, das exigências econômicas e políticas, do enraizamento social aos quais certas formas de saber empírico - principalmente as ciências humanas - estão comprometidas. Como Weber, Foucault enfatiza a necessidade de verificar quais as práticas que se repetem, que se legitimam e legitimam a constituição do saber, em que momento a forma de organização social dos homens afetou a sua produção ou mesmo as verdades que ela reivindica.

Estamos no âmbito das relações novamente, a constituição do saber, revelada por pequenas verdades inaparentes, insere-se no jogo da dominação, obscurecendo as relações instituídas para garantir a naturalização das regras e práticas institucionais e absolutizar aquilo que é relativo ${ }^{9}$.

5 Segundo Foucault, a aceitação tácita da lei e das regras é que permite reativar sempre o jogo da dominação, e "o grande jogo da história será de quem se apoderar das regras, de quem tomar o lugar daqueles que as utilizam, de quem se disfarçar para pervertê-las, utilizá-las ao inverso e voltá-las contra aqueles que as tinham imposto..." (pg. 25). A metodologia proposta por este autor vai além do poder jurídico ou visivel, buscando sua face invisível, molecular, que permeia a todos. É neste sentido que ele traça a história do Estado judiciário ("Sobre a Justiça Popular"), traz à tona um jogo particular de dominio das regras: ao substituir um tribunal arbitral na Idade Média por um conjunto de instituições estáveis e específicas que faz referência a uma regra universal de justiça, a burguesia tomou para si o direito de impor a sua justiça à todos...Foucault considera este histórico para apontar a tendência da direita em tratar o poder exclusivamente em termos jurídicos.

6 Os marxistas são o principal alvo da crítica de Foucault quando se fala de analisar o poder somente em termos do Estado, de dominação de classes ou somente em termos econômicos. Segundo Foucault, para uma análise genealógica do poder, não podemos nos ater unicamente à análise dos aparelhos do Estado, ou aos instrumentos de dominação de uma classe ou mesmo à sua significação econômica pura e simplesmente, pois "o poder em seu exercicio vai mais longe, passa por canais mais sutis, é muito mais ambígüo, por que cada um de nós é titular de um certo poder e, por isso, veicula o poder" (pg. 160).

7 Esta é a grande crítica de Foucault à análise fenomenológica do poder. Ele propôs, através da abordagem genealógica, que os problemas de constituição dos “objetos" podem ser desvendados dentro de sua trama histórica, ao invés de remetê-los a um sujeito constituinte.

8 Sobre o papel das técnicas de planejamento espacial, cremos que seria interessante um cruzamento deste texto da Microfísica do poder com o texto de Eliane Robert Moraes "O jardim secreto - notas sobre Bataille e Foucault" - Revista Tempo Social; Rev. Sociol. USP, S. Paulo, 7 $(1-2): 21-29$, out 95 .

9 Foucault adverte para a transformação do papel do intelectual, que, se antes se via como o portador de valores universais, deve reelaborar sua função ao assumir a responsabilidade política por aquilo que produz e divulga. Não é novidade que os intelectuais possam manipular seus conhecimentos ideologicamente; contudo, o que o autor critica é a afirmação de que a prática científica é acompanhada por uma ideologia justa e, portanto, natural e legítima. Ora, tal legitimação só ocorre por um efeito de reconhecimento das práticas científicas como as únicas possiveis e um desconhecimento de outras modalidades de relação. Nesse sentido vale a leitura de algumas questões levantadas por Foucault sobre o papel político do intelectual de hoje, não só no texto "Os intelectuais e o poder", mas ao longo da Microfísica do Poder(1979). 
O caráter relacional do poder é enfatizado $e$, indo às últimas conseqüências do que afirma Foucault, é muito dificil entender, por força do discurso do saber que constitui o nosso modo de pensar, essa sobredeterminação das práticas, das relações e da microfísica ou pulverização do poder. Mas, sem dúvida, constitui um alerta, sobretudo para a autoria institucional daquilo que julgamos tão natural em nosso saber.

Para Foucault as relações de poder não se passam fundamentalmente no âmbito das leis ơ do direito; ele propõe trazer à tona o jogo de dominação que se esconde na dimensão jurídica do poder e é categórico ao afirmar que o estudo do poder não deve se dar só em "termos de cessão, contrato, alienação, ou em termos funcionais de reprodução das relaçōes de produção", mas, sim, "em termos de combate, de confronto e de guerra" (1979, p.176). Assim, se quisermos analisar o poder, devemos fazê-lo por meio das relacōes com as quais ele permeia todo o corpo social, da constituição dos saberes, da trama histórica que o constitui.

Chamou-nos a atenção um tipo particular de efeito do poder - aquele sobre o corpo e o desejo dos indivíduos, pois, ao aceitarem docilmente as leis - que não são naturais, mas tiveram sua emergência em confrontos, do direito de obrigação - eles submetem seus corpos a um poder disciplinar que os classifica, distribui espacialmente, vigia e registra continuamente seus comportamentos.

Longe de analisar o poder como algo dado, Foucault o trata como ação, como exercícios múltiplos que atuam em todos os pontos do corpo social e que constituem as redes de relações. Ele encara o exercicio do poder menos em termos de aparelhos do Estado e mais como mecanismos e estratégias infinitesimais. O ponto de partida para a análise do poder seria o nível da microfísica, o nivel molecular do seu exercício.

O poder deve ser encarado como açąo, seu funcionamento se dá por meio de estratégias, de táticas. Para a sua compreensão, deve-se ter em mente a idéia de uma rede de relaçōes que articula e integra diferentes campos do poder (Estado, familia, escola, prisão, etc.). Cada um desses campos é ao mesmo tempo lugar de exercício de poder e de formação de saber. E não há saber neutro, todo saber vem acompanhado de produções ideológicas que derivam das próprias relações de poder. Ocorre que nas relações, os homens dominam outros homens, as classes dominam outras classes e a dominação em sua análise, implica em "se apoderar" de um sistema de regras que não tem em si significação essencial e lhe impor uma direção, dobrá-lo a uma nova vontade, a novas regras. É aqui que Foucault aponta para a necessidade do poder formar e difundir um saber que permita o dominio das regras do grande jogo que é a História. Assim, o que importa não é classificar os conteúdos das relações entre as estruturas econômicas e politicas, mas, sim, conhecer seu poder de formar, organizar e difundir um saber.

Todas estas questões levantadas por Foucault parecem uma boa porta de entrada para compreendermos os usos que estão sendo feitos do termo gênero no campo acadêmico, o jogo de poder e a produção de verdade que ele traz consigo.

A metodologia desenvolvida por Foucault para se estudar o poder 
compreende o estude das práticas, da microfísica, das relaçōes para se chegar a um tema, um objeto. Foi assim com a loucura, a justiça e a sexualidade entre outros, Foucault partiu das relaçōes, rompeu com as continuidades históricas, temporais e espaciais para revelar como estes temas se constituiam e se naturalizavam. Além disso, ele sempre buscou revelar a reciprocidade entre a produção de um saber correlacionado às relações de poder, desacreditando a idéia da revelação dos objetos através de um discurso científico universal e neutro.

Entendemos que uma boa compreensão da metodologia da análise do poder, de Foucault, da problemática que ele analisa na produção de saber, bem como de suas propostas de ação politica embasaram muitas das questões teóricas utilizadas na construção de muitas categorias de análise. Nesse sentido, o que fazemos aqui é tentar estender algumas de suas questões ao campo específico das relações de gênero.

Mesmo não utilizando o termo gênero ${ }^{10}$, Foucault problematizou a dificuldade em abandonar a ficção de sempre estar do "lado correto" dos objetos, entre eles o sexo, colocando em evidência os limites de um estudo do poder baseado no "correto" ou naquilo que se supõe verdadeiro e universal. Ele propõe fazer uma leitura política dos limites entre o masculino e o feminino, pois foi somente a partir de um determinado momento que as identidades sexuais foram questionadas; foi a partir daí que gênero passou a possuir importância política.

Contrário à imagem biológica e natural da ciência, Foucault expõe seu objetivo de revelar a constituição dos discursos sobre o sexo, privilegiando as relações que o produziram. Ele se empenhou em destronar o "sexo rei"11, desmontando as relações fixas e a hierarquia das práticas sexuais que se pretendem "verdadeiras" e revelando o sexo como um poderoso instrumento de controle e poder. Na medida em que as relações fixas sobre sexualidade são questionadas, Foucault desmonta o domínio dos discursos sobre sexualidade e propōe uma análise política dos limites entre masculino e feminino, enfatizando que, no século XVIII, o que importava era apenas o sexo masculino, e que o sexo feminino só foi estudado depois que a mulher começou a adquirir importância médico-social.

Para Foucault, a idéia de liberação da sexualidade centrada apenas na dimensão sexológica, que reduz tudo ao sexo, não representa avanços politicos já que ela fixa as pessoas à sua sexualidade e normatiza suas práticas, revelando-se mais como um dispositivo de sujeição às relações fixas de dominação sexual existentes. Nesse sentido ele criticava os movimentos de homossexuais americanos muito presos à reivindicação dos direitos de sua sexualidade e elogia os movimentos de liberação das mulheres que partem de um discurso próprio para chegarem a uma verdadeira dessexualização.

10

11

Como veremos mais adiante, este é um termo que começou a ser utilizado na década de 80 . Creio que este termo utilizado por Foucault pode ter mais de um significado, ele tanto pode se referir à práticas sexuais ditas "corretas", que recheiam os discursos sobre a sexualidade, quanto aos cânones masculinos, ou o culto ao falogocentrismo, que ainda hoje alimentam muitas análises. 
O que há de interessante e criativo nos movimentos de liberação das mulheres segundo Foucault, são os objetivos econômicos e políticos que movimentam suas lutas contra uma forma particular de poder, de controle sobre elas. Por meio dos movimentos feministas, as mulheres estāo conseguindo tirar proveito da sexualidade que procura sujeitá-las ao reinventar um tipo próprio de existência politica, econômica e cultural.

Nos anos 80 , as feministas norte-americanas começaram a utilizar o termo "gênero" como uma forma de introduzir uma noção relacional em seu vocabulário de análise. A historiadora norte americana Joan W. Scott (1990) afirma que o termo começou a ser utilizado por pesquisadoras feministas que insistiam no caráter fundamental social das distinçōes fundadas sobre o sexo".

Scott propôs desenvolver o termo "gênero" como uma categoria de análise, criticando o uso de representações sobre o masculino e o feminino que levam a construções muito subjetivas, bem como a fixação exclusiva sobre as questões relativas ao "sujeito". Aqui podemos lembrar a crítica de Foucault sobre remeter os problemas de constituiçāo das relações de poder exclusivamente sobre um sujeito constituinte.

Além de traçar um histórico dos usos que estão sendo feitos de gênero, Scott propõe articular quatro elementos para torná-lo uma categoria de análise: simbolos culturalmente disponiveis; conceitos normativos de interpretação do sentido dos símbolos; noções de política, instituição e organização social; e a noção psicanalítica de identidade subjetiva. Entretanto, uma questão sobre o trabalho de Scott tem inquietado algumas feministas contemporâneas - apesar de ajudar a introduzir a categoria de gênero no feminismo, esta autora insiste em um referencial: as diferenças sexuais.

A definição de gênero de Scott não consegue destronar o sexo rei, e a estratégia política do feminismo parece pedir outras reflexões renovadas sobre gênero. Neste sentido, os estudos de Judith Butler (1990) e suas propostas de ação política parecem ser mais coerentes com as idéias de Foucault e fornecem uma base para a elaboração de questões teóricas necessárias à construção relacional, situacional e performática de gênero. A subversão de identidades proposta por Butler rompe com três pressupostos que atrapalhavam o debate em torno de gênero: a naturalização do sexo; a coerência do gênero em relação ao sexo; e a polarização tanto para o sexo quanto para o gênero.

De certa forma isso se soma ao empenho de Foucault em destronar o sexo rei e a corte de identidades sexuais, desmontando as relaçōes fixas e a hierarquia das práticas sexuais. Esses posicionamentos não são privilégios de intelectuais estrangeiros; no Brasil, Jurandir Freire Costa ${ }^{12}$ defende a temporalidade das identidades constitutivas de gênero apontando para a diversidade de relações que poderiam existir, "encontrando seus códigos não nas instituiçōes mas em suportes eventuais"(p. 133). Assim como Foucault e Butler, Freire Costa aponta para relaçōes estratégicas, situacionais, em que os papéis existem, mas podem ser invertidos, pois não são fixos. Este é o caráter

12 Freire Costa, J. "O sujeito em Foucault: estética da existência ou experimento moral?". Tempo Social; Rev . Sociol. USP, S. Paulo, 6 (1-2): 121-138, outubro, 1995. 
relacional de gênero, que só existe quando atuado e que entendemos, é a articulação de gênero que mais se aproxima do quadro analítico das relações de poder esboçado por Foucault.

As questōes levantadas até agora parecem uma boa porta de entrada para compreender melhor alguns aspectos importantes da vida militar: a formação profissional e as relaçōes de gênero decorrentes da integração feminina. Talvez uma boa tradução dos questionamentos dos autores citados aqui para o nosso universo de pesquisa seria um posicionamento que nos remete invariavelmente à questão de poder, embutido nas relações sociais e conferido àqueles que detém as posições mais socialmente valorizadas. Entendemos que, em seu conjunto, as teorias que consideramos neste estudo fazem refletir sobre os mecanismos que reforçam as relações de poder vigentes.

\section{A ACADEMIA}

A Academia da Força Aérea - AFA - é um estabelecimento de ensino superior que integra o sistema de formação e aperfeiçoamento do pessoal do Ministério da Defesa - Comando da Aeronáutica, cuja finalidade é a formação, em nível superior, dos Oficiais da Ativa da Força Aérea Brasileira. A Academia é o local de estudo, moradia, alimentação, assistência médica-hospitalar e lazer dos cadetes durante o período de aulas nos quatro anos de curso. Ao se formar na Academia, o cadete recebe o título de "Aspirante-a-Oficial" e passa a fazer parte do rol de oficiais da hierarquia da Aeronáutica.

Hierarquia da Aeronáutica:

Oficiais:

\begin{tabular}{l|l|l}
\hline Oficiais Generais $^{*}$ & Oficiais Superiores & Oficiais Subalternos \\
\hline Tenente-Brigadeiro & Coronel & Capitão \\
\hline Major-Brigadeiro & Tenente-Coronel & $1^{\circ}$ Tenente \\
\hline Brigadeiro & Major & $2^{\circ}$ Tenente \\
\hline & & Aspirante-a-Oficial \\
\hline
\end{tabular}

Praças:

\begin{tabular}{l}
\hline Subtenente \\
\hline $1^{\circ}$ Sargento \\
\hline $2^{\circ}$ Sargento \\
\hline $3^{\circ}$ Sargento \\
\hline Cabo \\
\hline Soldado \\
\hline
\end{tabular}


Os cursos de formação de oficiais da Academia se dividem em três de acordo com os "Quadros": Aviação - CFOAv, Intendência - CFOInt e Infantaria - CFOInf, todos com duração de quatro anos. O ingresso na Academia se dá mediante concurso vestibular de âmbito nacional para os quadros de Infantaria e Intendência, sendo este último o primeiro a aceitar mulheres em $1996^{13}$. No caso específico da Aviação, a maioria dos ingressantes vem da Escola Preparatória de Gadetes da Aeronáutica - EPCAR - localizada em Barbacena, Minas Gerais, e anualmente são disponibilizadas em torno de vinte vagas a serem preenchidas por meio do vestibular.

$\mathrm{Na}$ Academia, em termos de formação profissional, destacam-se o Corpo de Cadetes da Aeronáutica e a Divisão de Ensino, com oficiais comandantes dos Esquadrões, instrutores militares e professores civis. $\mathrm{O}$ ensino $^{14}$ é dividido em "geral", que visa dar ao cadete um embasamento cultural necessário para o prosseguimento na carreira, "militar", que compreende os procedimentos militares comuns aos três quadros, e "técnicoespecializado", que prioriza o conhecimento técnico necessário para a atuação dentro do Quadro escolhido.

O Quadro da Aviação é considerado a "atividade-fim" da Força, os/as cadetes deste Quadro precisam desenvolver as qualidades de pilotos militares, executando decolagens, aterrissagens, procedimentos de emergência, procedimentos de aproximação, dominando o avião em manobras de precisão, acrobacias, vôos de formatura e vôo por instrumentos.

O Quadro de Intendência é responsável pela máquina administrativa e burocrática da Força, os/as cadetes-intendentes são os mais envolvidos com as atividades acadêmicas, principalmente nas áreas da administração, suprimentos e serviços. Desenvolvem atividades relacionadas à ciência e tecnologia da gestão econômico-financeira e se preparam para cuidar da parte administrativa da Força e para as tarefas exigidas em combate de superfície integradas ao sistema logístico.

O Quadro de Infantaria da Aeronáutica é o mais "moderno" da Academia, os cadetes Infantes estudam métodos de defesa e segurança das instalações militares, emprego de defesa antiaérea de aeródromos e pontos sensiveis, comando de frações de tropas e de contra-incêndio, legislação militar, emprego de armamentos, serviço militar e mobilização.

Durante o curso, os cadetes vivem em regime de internato, podendo sair apenas nos finais de semana ${ }^{15}$ - quando não estão "de serviço" ou "presos". Todos os cadetes obedecem a uma rotina comum em termos de horários que reproduzimos abaixo.

13 As mulheres passaram a ser admitidas no Curso de Formaçāo de Oficial Aviador somente em 2003 e devem se formar no final de 2006.

14 O ensino era composto da maneira que relatamos até 2004, quando houve a implantação de um Curso de Administração concomitante aos Cursos de Formação de Oficiais. Como as conseqüências desta implantação sobre a formação dos cadetes ainda são desconhecidas, por serem recentes, optamos por descrever o ensino que vigorou até 2003 neste artigo.

15 Além dos fins de semana, os cadetes podem sair ocasionalmente, durante a semana, através dos "licenciamentos" concedidos pelo Comando do Esquadrão, conseguidos mediante o preenchimento de guias no quai eles devem justificar para onde e para quê vão sair. 
Rotina "oficial" do Cadete da Aeronáutica":

$\begin{array}{lll}6 \mathrm{~h} 00 \mathrm{~min} & \text { Alvorada } \\ 6 \mathrm{~h} 30 \mathrm{~min} & \text { Café da Manhã } \\ 7 \mathrm{~h} 30 \mathrm{~min} / 11 \mathrm{~h} 50 \mathrm{~min} & \text { - } & \text { AulasiNôo } \\ 12 \mathrm{~h} 05 \mathrm{~min} & \text { - } & \text { Parada Diária } \\ 12 \mathrm{~h} 15 \mathrm{~min} / 13 \mathrm{~h} 00 \mathrm{~min} & - & \text { Almoço } \\ 13 \mathrm{~h} 45 \mathrm{~min} / 15 \mathrm{~h} 25 \mathrm{~min} & - & \text { Aulas Nôo } \\ 15 \mathrm{~h} 45 \mathrm{~min} / 17 \mathrm{~h} 15 \mathrm{~min} & - & \text { Educação Física } \\ 16 \mathrm{~h} 00 \mathrm{~min} / 18 \mathrm{~h} 00 \mathrm{~min} & - & \text { Visita Médica } \\ 18 \mathrm{~h} 30 \mathrm{~min} / 19 \mathrm{~h} 30 \mathrm{~min} & - & \text { Jantar } \\ 19 \mathrm{~h} 35 \mathrm{~min} / 21 \mathrm{~h} 50 \mathrm{~min} & - & \text { Tempo Livre } \\ 22 \mathrm{~h} 00 \mathrm{~min} & \text { - } & \text { Silêncio. } \\ & \end{array}$

O horário reservado à atividade intitulada "tempo livre" (19h35min$21 \mathrm{~h} 50 \mathrm{~min})$ é na verdade o horário utilizado para a atividade que os cadetes chamam de "pernoite". Neste horário, os cadetes entram e permanecem em forma para receber recados, orientações, avisos e reuniões com seus líderes (cadetes do $3^{\circ}$ e $4^{\circ}$ anos). Este horário é utilizado também para cobranças, vistorias de alojamento e de uniformes e exercicios "corretivos" - em que os cadetes do $1^{\circ}$ ano, principalmente, recebem ordens para 'pagar' flexões e exercícios físicos pelos seus atrasos e "alterações" ${ }^{17}$.

Todos os deslocamentos realizados pelos cadetes precedem de uma "formatura"; por exemplo, do rancho (restaurante) para as salas de aula, ou das salas de aula para o Corpo de Cadetes. A parada diária ocorre no 'pátio dos cadetes', quando os quatro Esquadrões desfilam conduzidos pela equipe de serviço dos cadetes e quando se realiza a troca de comando de "cadete-dedia" frente aos oficiais do Corpo de Cadetes e às autoridades militares e/ou civis que se encontram na Academia.

Há áreas restritas aos cadetes de acordo com o ano; por exemplo, cadetes do $1^{\circ}$ e $2^{\circ}$ anos não podem permanecer na frente dos "quadros de avisos"18 de turmas do $3^{\circ}$ e $4^{\circ}$ anos, e todos eles são proibidos de ultrapassar o corredor que leva à seção de avaliação deste setor da Academia, bem como de adentrar na sala dos professores. Os bedéis permanecem nos corredores da Divisão de Ensino durante o horário de aulas. São eles que tocam a campainha e ficam à disposição dos cadetes e professores no caso de alguma necessidade. Eventualmente oficiais percorrem os corredores das salas de aula e, através dos visores das portas e dos "carômetros"19 , vigiam e controlam

16 Esta rotina também sofreu alteraçōes consideráveis em razão da implantação de um curso de Administração na Academia em 2004. Entretanto, pelas mesmas razōes acima expostas, consideramos a rotina antes da implantação do curso de Administração.

17 São consideradas alteraçōes os pequenos deslizes que os cadetes cometem como: falar durante as formaturas, rir, ficar relaxado, faltar às revistas, nāo se apresentar para os cadetes mais antigos, nāo executar um movimento de modo firme, chegar atrasado, não cantar as cançōes..

18 Quadros emoldurados e protegidos por uma porta de vidro que fica no pátio da Divisāo de Ensino, onde são afixados: os horários e as atividades previstas para a semana, conceitos, notas e avisos gerais que se referem aos cadetes de determinado esquadrão. Há quatro quadros deste tipo e cada um corresponde a um dos quatro esquadrões.

19 O "carômetro" constitui uma montagem com fotos $3 \times 4$ dos cadetes que é afixada por cima do visor e revela a posição que eles devem ocupar na sala de aula, sendo que os cadetes melhores classificados devem ocupar as carteiras do fundo, e os últimos classificados ficam nas primeiras fileiras, de acordo com a ordem das fotos. 
o comportamento dos cadetes, "anotando" aqueles que se encontram exercendo atividades "não previstas", como por exemplo, demonstrar sono ou mesmo cochilar.

Há atividades especialmente elaboradas com a finalidade de perceber o fortalecimento de companheirismo entre os cadetes, dentre elas os "exercícios de campanha", em que os cadetes saem da rotina da Divisão de Ensino e do Corpo de Cadetes e participam de acampamentos que simulam situações que eles podem vivenciar no futuro, como oficiais. Nestas ocasiões, os cadetes freqüentam várias "oficinas" de sobrevivência na selva, procedimentos de socorro, marcham em terreno irregular carregando armamento e mochilas, atravessam cursos d'água, realizam exercícios de navegação e orientação e são incentivados a auxiliar os companheiros nas atividades propostas. O objetivo destes exercícios, segundo os oficiais, é observar como os cadetes agem numa situação-limite, para procurar corrigir desvios de conduta ou mesmo descobrir comportamentos surpreendentes de companheirismo e cooperação entre eles.

Os cadetes que permanecem na Academia nos finais de semana podem desfrutar de atividades de lazer organizadas por diversos "clubes" dirigidos por eles e supervisionados por oficiais. Esses clubes são denominados de acordo com a atividade que lá se desenvolvem: Clube de vôo a vela, de aeromodelismo, de plastimodelismo, de história militar, de literatura, de informática, de tiro, "das Gerais" (de tradições de Minas Gerais), de Tradições Gaúchas, conjunto musical ("Banda"), grupo teatral, de Tradições Nordestinas e de Montanhismo.

Aos cadetes é permitido o uso de aparelhos telefônicos celulares no âmbito da Academia, não sendo permitido seu uso nos horários de aulas e o seu transporte em deslocamentos e formaturas. Notebooks são permitidos apenas nos alojamentos.

Todos os cadetes recebem um pequeno auxílio financeiro (soldo/salário) durante o curso na Academia. Os períodos de férias geralmente ocorrem após a solenidade de entrega do "Espadim" - símbolo do cadete da Aeronáutica - aos cadetes do primeiro ano, em julho, e após o "Aspirantado", quando os cadetes que terminaram o quarto ano são declarados Aspirantes-aOficiais, em dezembro.

Nos primeiros anos na Academia, os cadetes passam por instruções, rituais e orientações em que são constantemente incentivados a cultivar a igualdade entre eles, visando ao desenvolvimento dos valores e atitudes próprios aos militares - principalmente da disciplina. Nos últimos anos, eles passam a atuar como "líderes", comandando cadetes e executando funções próximas àquelas vivenciadas pelos oficiais, visando principalmente ao desenvolvimento do princípio de hierarquia.

A classificação permeia a vida de todos os cadetes; ela pode ser dada a partir do mérito individual indicado pelo resultado dos conceitos obtidos na Divisão de Ensino - por meio das notas - e no Corpo de Cadetes - por meio do "desempenho militar". As médias obtidas pelos cadetes nestes dois setores da 
Academia resultam nas listas de classificação ${ }^{20}$, que determinam os números $(01,02,03 \ldots$ até o último classificado) de identificação e a respectiva posição que os cadetes devem ocupar hierarquicamente a cada ano. $\mathrm{Na}$ lista de classificação destaca-se a posição de primeiro colocado; trata-se da posição mais disputada e cobiçada visto que revelam os cadetes considerados "notáveis" entre os de mesmo curso, de mesmo esquadrão e quando chegam ao $4^{\circ}$ ano, entre todos os cadetes, pois somente os melhores classificados podem ocupar posições no Estado Maior do Corpo de Cadetes.

Além da classificação individual por notas, há uma classificação que independe do mérito, a classificação por "antiguidade"; esta classificação é regulamentada através de uma NOREG - AFA ${ }^{21}$ que, entre outras, versa sobre a situação militar do cadete. Em primeiro lugar, estabelece que a precedência hierárquica entre os cadetes baseia-se na ordenação decrescente dos cursos, assim, os cadetes do $4^{\circ}$ ano seriam mais antigos do que os do $3^{\circ}$, que seriam mais antigos que os do $2^{\circ}$, que por sua vez seriam mais antigos que os do $1^{\circ}$ ano. Em segundo lugar, estabelece que, dentro do mesmo Quadro, a antiguidade é dada pela média da classificação geral obtida nas séries anteriores, exceção feita ao $1^{\circ}$ ano, cuja precedência hierárquica é dada pela classificação obtida na EPCAr para os cadetes aviadores e pela classificação obtida no processo seletivo (vestibular) para os demais. O terceiro ponto estabelecido pela NOREG trata da antiguidade entre os cursos que estabelece que os cadetes aviadores são mais antigos que os intendentes da mesma série, e estes, são mais antigos que os cadetes de Infantaria. Neste caso, não se trata da classificação produzida pelo mérito, mas sim de um mecanismo legal que garante a precedência hierárquica de um Quadro sobre o outro.

Os cadetes podem vivenciar uma multiplicidade de papéis no decorrer de sua formação na Academia, de acordo com o sentimento de pertença a determinados grupos - Esquadrão, Quadros, equipes esportivas, homens, mulheres, Estado Maior, Cadeia de Comando, Conselho de Honra, Sociedade do Cadetes, grupo de teatro, de vôo a vela, bandas, etc., com as características próprias - filhos de militares, religião, gênero, classe social, região geográfica de procedência, etc., mas, também, segundo a posição que ocupam em determinadas situações. Por exemplo, um cadete aviador do quarto ano pode ser mais antigo que uma cadete de sua turma, porém se ela for a primeira classificada do Curso de Intendência, ocupará o posto de cadete líder da Intendência, e ocupando uma posição no Estado Maior do Corpo de Cadetes. O cadete classificado em primeiro lugar do Curso de Infantaria também ocupará uma posição de destaque no Estado Maior do Corpo de Cadetes; neste caso, o status dos cadetes independem da antiguidade dos Quadros. Há outros casos em que o status do cadete independe da antiguidade entre os Quadros e mesmo entre os esquadrões como por exemplo, os atletas que se destacam em competições esportivas.

20 As listas de classificação determinam as posições entre os cadetes do mesmo esquadrão e do mesmo Quadro (são três listas de classificação em cada esquadrão).

21 Trata-se de uma regra com base na portaria DEPENS nœ 094/DE, de 6 de 9 de abril de 1996 , que estabelece normas referentes à escolaridade, matrícula, ensino, e outros aspectos relativos à formação do cadete na AFA, entre elas, a precedência hierárquica. 
Em termos estruturais, a Academia se apresenta nos moldes da clássica descrição de Weber sobre as instituições militares - embasada predominantemente em uma administração burocrática e orientada por um conjunto de normas e regras que, dentre outras, determinam os direitos e deveres de cada um. Entre os elementos que compõem o modelo burocrático, conforme ressalta Leirner, a disciplina e a hierarquia são considerados os "pilares básicos" da estrutura militar moderna.

O espaço é um importante elemento de controle na Academia, como descrito por Foucault, o conjunto arquitetônico da instituição militar deve compor uma estrutura favorável à vigilância e observação de todas as pessoas que transitam por ele. Neste sentido, todos os deslocamentos que os cadetes realizam entre o Corpo de Cadetes e a Divisão de Ensino podem ser observados, pois eles passam por um corredor conhecido por "parabolóides" enormes estruturas de concreto sustentadas apenas por colunas que constituem um corredor. O pátio principal do Corpo de Cadetes abriga o pátio da bandeira com os mastros, e deste local é possível observar todos os prédios de alojamentos dos cadetes; ao fundo, vê-se o corredor dos "parabolóides" e o brasão da Academia estampado no prédio de alojamentos de cadetes do $1^{\circ}$ e $2^{\circ}$ anos. Em cada coluna dos parabolóides mais próximos ao Corpo de Cadetes, estão afixadas as placas das turmas que já se formaram na Academia.

A própria Divisão de Ensino, com seus corredores percorridos por bedéis, oficiais e professores, com suas portas dotadas de "visores" e de "carômetros" afixados sobre eles, que, dentre outras coisas, possibilitam observar se os cadetes cumprem a disposição espacial pré-estabelecida na sala de aula, revelam um ambiente estruturado de forma a favorecer a observação dos cadetes. Em quase todos os locais por onde os cadetes passam, há símbolos, inscrições, monumentos e placas que lembram sempre que trata-se de um ambiente militar.

Ao retomar algumas questões levantadas por Foucault para articulá-las às discussões sobre gênero, percebemos que seu posicionamento teórico remete à reflexão sobre os mecanismos que reforçam as relações de poder vigentes quando aprisionamos indivíduos de acordo com conceitos universalizantes e "padrões" ou mesmo com seu sexo. E tanto a formação profissional como gênero pressupõem sempre um fazendo, um processo, por meio de vivências de múltiplos papéis e situações.

Segundo os relatos ${ }^{22}$, tanto os cadetes quanto alguns oficiais faziam piadas sobre a presença das cadetes na Academia, como diz uma cadete intendente:

22 Na exposição dos relatos, suprimimos propositalmente alguns dados que poderiam revelar a identidade dos/as cadetes, tais como o ano ou a turma. 
Quando a gente entrou aqui, teve muita discriminação também de oficiais; isso era uma coisa que desestimulava muito a gente; tinha piadinhas: - ah, vai prô tanque lavar roupa que lá é o seu lugar... E isso desestimulava totalmente a gente, tanto é que a gente falava que quando a gente saisse daqui e estivesse na rua e um homem passasse por mim e falasse - tanque! ele vai levar um murro na cara! (risos) E uma coisa que tá tão assim fervendo dentro da gente, a gente já ouviu tanta coisa, tantas besteiras... A gente levou isso nas reuniões prá trabalhar, mas para os oficiais também é dificil, porque foge do controle deles também.

Os cadetes em geral admitem uma posição "machista" em relação à presença feminina na Academia, mas não deixam de valorizar aquelas que se destacam como militares e contribuem para incentivar os cadetes da turma com sua disposição. Como revela esta fala de um cadete aviador:

A senhora deve ter percebido aqui que a gente tem um pensamento é... masculino... né?

Machista?

É, machista. Pôrra, a gente sempre teve um pensamento machista aqui, não desprezando porque tem muitas meninas que, pô, são melhores que muitos homens, entendeu? Coisas do exec por exemplo, pô, na hora que você tá cansado assim, na caminhada do acampamento, você olha do teu lado e vê uma menina com uma mochila igual a tua , "mosquetão", capacete e te passando, entedeu? Isso ai levanta o moral!

Os cadetes do primeiro esquadrão misto parecem ter assimilado bem a questão do pioneirismo da turma, do Esquadrão, e não só das mulheres. Através de trecho de entrevistas com dois deles é possivel perceber que, ao final do curso, eles se identificam como uma turma de pioneiros. Vejamos:

Todos nós somos pioneiros, porque eu não considero somente elas pioneiras, eu considero a turma entendeu? Com certeza tem o mérito particular delas porque elas sentiram dificuldades, mas não deixa de afetar a turma toda. (Cad Int)

Quanto às brincadeiras por fazermos parte da primeira turma com mulheres, a gente sempre tentou dar um enfoque de que a turma toda era pioneira e não só elas, porque elas estãe com a gente. (Cad Av)

Em sua maioria, porém, os/as cadetes relatam que o relacionamento entre homens e mulheres vai "melhorando" no decorrer dos quatro anos, em vista do "amadurecimento" de grande parte dos cadetes, que faz com que o respeito pelas diferenças apareça. Como mostra este trecho da entrevista com um cadete de Infantaria do $4^{\circ}$ ano:

A cada ano, o relacionamento com as meninas foi melhorando, a gente vai aprendendo a respeitar; a própria turma vai mudando, tanto que hoje ainda tem aqueles que não aceitam as mulheres aqui, mas respeitam. Eu me relaciono tranqüilamente com elas.

Algumas mulheres atribuem à participação feminina o respeito $\mathrm{e} o$ amadurecimento que os cadetes passaram a apresentar pelas cadetes. Conforme o relato de uma cadete do $4^{\circ}$ ano: 
Eu acho que prá eles a entrada das mulheres deu uma maturidade muito grande prôs cadetes; eles começaram a entender melhor as mulheres inclusive lá fora. Quebraram um pouco aquela coisa de que mulher é "fraquinha"; não, eles começaram a ver que mulher também pode ser uma boa profissional; a mulher sempre tira boas notas, então eles começaram a formar uma outra imagem das mulheres. Acho que eles amadureceram mais em termos de relacionamento homem - mulher, aprendendo a respeitar as diferenças.

A maioria dos cadetes, homens e mulheres, relatam que o reconhecimento da identidade militar das mulheres se dá em situações em que todos precisam de todos para se saírem bem, como por exemplo durante os "exercícios de campanha". Reproduzimos aqui o depoimento de uma cadete que fala especificamente sobre um exercício de campanha em que as mulheres se esforçaram para sobrepor a identidade militar sobre a feminina e foram reconhecidas como "guerreiras" pelo grupo:

No terceiro ano a rivalidade homem $x$ mulher ficou mais calma no decorrer do ano, o marco foi o exercício de campanha. Foi muito penoso para todos, e eles (cadetes homens) viram que a gente, porque tinha menina menstruada no exercício, e foi muito horrivel prá gente passar por aquele período e ainda por cima, menstruadas. E isso é muito das meninas da minha turma, é da gente querer provar e mostrar que a gente pode, que a gente é capaz, até chegar e estourar o limite e ter um problema no joelho, mas as meninas da nossa turma provaram ter muita raça. E o exercício de campanha 3 tem água e, por causa da água, a gente entrava na água e aí tava de modess (absorvente feminino), aí modess tem floc gel (espécie de granulado minúsculo que, em contato com líquido forma flocos gelatinosos) né? Aí fica aquele negócio desse tamanho, manchado, e as meninas lá no exercício, sem reclamar, pô, aí eles viram: "- pô elas são guerreiras!" "Eu não sei se eu agüentaria fazer o que elas estão fazendo!"

Em sua maioria, os cadetes (homens) que foram inicialmente contrários à participação das mulheres mudam de opinião no decorrer do curso, e mesmo ressaltando os tratamentos diferenciados no trato entre homens e mulheres, a maioria deles percebe o esforço de suas companheiras para desenvolverem uma identidade militar. Vejamos os relatos de alguns deles:

A Academia não tava preparada: tem esse lado machista; eu acho que no mundo hoje em dia as Forças Aéreas estão trazendo bastante as mulheres, mas eu acho que aqui eles tinham que preparar mais. Não é só aqui que tem esse machismo; uma vez veio um piloto da França que contou que lá tinha uma piloto de Caça e eles queriam desligar ela porque eles não queriam mulher lá na Caça, também lá. É até uma questão filosófica da guerra; assim, quem vai normalmente e quem morre é o homem, né? Porque o problema da mãe, da mulher estar morrendo fica um negócio meio ruim. Mas eu acho que quando eles colocaram a mulher aqui foi mais uma jogada política de promover a Força Aérea, como uma Força mais "aberta"...

Mas eu acho que as meninas são competentes também porque se você olhar na $D E$, elas tiram notas muito boas, elas são competentíssimas. Pensando bem, eu acho que a Força Aérea até ganhou porque elas são mais detalhistas; às vezes a gente escuta que mulheres são mais honestas também, homem já vê as coisas de um modo diferente. (Cad $\mathrm{Av}-4^{\circ}$ ano) 
Eu acho que tem mulher que realmente acochambra e tem mulher que realmente se esforça. Hoje, por exemplo, eu tive uma prova; o "mosquetão" (fuzil) é um peso tanto prá homem como prá mulher, pô, e tem posição que a gente fica que eu, que gosto de malhar, pesa. E eu fico olhando prás meninas e vejo que, pô tem umas que agüentam! Ai você olha assim e vê: pôrra, tem menina que agüenta, caramba! Então você vê que as mulheres que estão aqui se for comparar algumas que lá fora não gostam de fazer nada, só de curtir a vida, que vivem em função do pai e da mãe, pô; a gente vê que elas são pessoas que realmente estão lutando por um ideal. Também o que elas passam? A mesma coisa que a gente que é homem. Ao mesmo tempo, elas são acochambradas não porque elas querem, os oficiais, por si próprios, por serem homens, eles acochambram. (Cad. Int. $3^{\bullet}$ ano)

Os cadetes mais antigos (homens e mulheres) nos oferecem interpretaçōes de como a mulher passou a ser vista na Academia, decorrido os quatro anos de sua participação :

Prá instituição eu acho que trouxe um pouco mais de educação, ficou um ambiente mais tranqüilo. nāo tão exaltado. A gente vê isso muito pelos namoros que comecaram a acontecer. Muitos cadetes que a gente chama de "bate-mal", que tentava pegar todo mundo no erro, fazia 'fobs'(ficha de observação). fazia todo mundo pagar, quando namorava parecia que ele se transformava, parecia que ele tinha uma coisa boa dentro dele que ele conseguia externar quando comecava a namorar, ai ele virava humano. As vezes o pessoal passava e ele tava com a namorada rindo, a gente nem acreditava: aquele cara ri!

O ambiente também ficou não digo mais ético, mas mais... porque aqui se falava muito palavrāo e parece que deu uma levantada no nivel. e eu acho que as instituiçōes quando passam a aceitar mulheres, elas têm uma grande parcela de aprimoramento porque passam a reunir pessoas de universos bem diferentes. (Cad Int)

O discurso oficial dos militares reconhece o desempenho "positivo" do grupo feminino ao final de quatro anos de acompanhamento da implantação do Curso de Formaçāo de Oficiais Intendentes (CFOInt):

O acompanhamento dos grupos mistos nas atividades acadêmicas revelou que, inicialmente, as cadetes destacavam-se em todos os envolvimentos na Divisão de Ensino: participação nas aulas, demonstração de interesse, criatividade e seriedade. Com o passar dos meses, os cadetes adotaram condutas semelhantes. Como resultado, houve uma elevação no nível desses grupos com conseqüente melhora de qualidade no preparo profissional.

Nota-se, com isso, que os cadetes foram alavancados pelo comportamento de suas companheiras de curso, evitando uma condiçāo de desvantagem... houve uma mudança de comportamento dos cadetes dos Cursos de Formação de Oficiais, mais evidente no CFOInt, com elevação da qualidade individual e grupal, melhora de atitude diante de assuntos profissionais e uma postura de melhor entendimento, aceitação e maior respeito com relação à mulher no campo profissional...

Comissão de Acompanhamento do CFOInt Feminino - Relatório Final, março de 2000, p. 9

Se por um lado, a chegada das mulheres na Academia da Força Aérea provocou algumas transformações anteriormente impensáveis, principalmente em termos de equivalência ou mesmo de relações de superioridade hierárquica entre mulheres e homens, por outro lado, há que se considerar que estas transformaçōes ocorreram concomitantemente aos vários obstáculos 
decorrentes da tradição masculina que permeia as instituições militares, traduzidos principalmente na forma de procedimentos que reforçam a divisão tradicional dos papéis sexuais e impingem à mulher uma limitação em sua participação social.

As dificuldades ainda ocorrem, causadas por comportamentos preconceituosos isolados, que ocasionam mal-estar no segmento feminino e reforçam comportamentos defensivos; entretanto, a elevação da qualidade na formação profissional conseqüente do esforço notável da maioria das cadetes das primeiras turmas é o aspecto mais valorizado no discurso oficial acerca da inserção das mulheres na Academia.

A questão do poder e da identidade permeia todas as relações vivenciadas pelos cadetes. Estas relações se concretizam através das normas, da vigilância, da obediência, da conduta ético-moral e de todos os padrões de conduta e valores cultivados no interior da caserna. Tradicionalmente, estas relações se constroem de forma diferente para homens e para mulheres militares, legitimando a divisão social dos papéis sexuais. Porém, apesar de toda discriminação que existe e garantida por mecanismos tradicionais, como por exemplo, a hierarquia e a disciplina, pelo discurso oficial e até mesmo por novas formas de relação entre homens e mulheres dentro da instituição militar, a admissão das mulheres na AFA abre espaços que permitem pensar na subversão do paradigma tradicional ou mesmo na igualdade entre homens e mulheres quando consideramos a profissão militar.

\section{REFERÊNCIAS BIBLIOGRÁFICAS:}

BUTLER, Judith. Gender trouble: feminism and the subversion of identity. Londres: Routledge, 1990.

CASTRO, Celso. O espírito militar - um estudo de Antropologia Social na Academia Militar das Agulhas Negras. Rio de Janeiro: Jorge Zahar, 1990.

FOUCAULT, Michel. Microfísica do poder. Rio de Janeiro: Graal, 1979.

FOUCAULT, M. Vigiar e punir: nascimento da prisão. Petrópolis: Vozes, 1977.

FREIRE COSTA, Jurandir. "O sujeito em Foucault: estética da existência ou experimento Moral ?". Revista Tempo Social. São Paulo: USP, 7 (1-2):121-138, out/1995.

GOFFMAN, Erving. Estigma- Notas sobre a Manipulação da Identidade Deteriorada. Rio de Janeiro: Zahar, 1978.

GOFFMAN,Erving. Manicômios, prisões e conventos. São Paulo: Perspectiva, 1996.

LEIRNER, P. C. Meia volta volver - um estudo antropológico sobre a hierarquia militar. Rio de Janeiro: Fundação Getúlio Vargas, 1997

SCOTT, JOAN. "Gênero: uma categoria útil de análise histórica". Revista Educação e Realidade. Porto Alegre: 16 (2): 5-12, jul/dez, 1990.

WEBER, Max. "Ensaios de sociologia". In GERTH, H.H. e MILLS, C.W. (orgs.) Max Weber - Ensaios de sociologia - Rio de Janeiro: Zahar , 1979.

WEBER, Max. Economia e sociedad. Volume II. Bogotá: Fondo de Cultura Economica, 1977. 